\title{
SOME EFFECTS OF BARLEY GRASS SEED ON YOUNG SHEEP
}

\author{
M. J. Hartley \\ Soil and Field Research Organisation, Ruakura A gricultural \\ Research Centre. Hamilton
}

\section{A bstract}

Studies were made of the effects of barley grass on young sheep. Up to $8 \mathrm{~kg}$ per lamb loss of weight gain during summer has been shown to be due to barley grass seed damage. Seed in the eyes caused the most rapid growth check but irritation to nostrils, mouth, and skin all contributed. Lambs were affected far more than adult sheep and differences between breeds of sheep were sufficient to consider change of 'breed where barley grass was troublesome. The beneficial effects and disadvantages of herbicide control are discussed in relation to density of barley grass infestation.

\section{INTRODUCTION}

BARLEY GRASS (Hordeum spp.) is generally considered to be an undesirable pasture species largely because of contamination of wool and the damage it does to lambs' pelts. However, there are farmers who consider it advantageous as a source of autumn feed as it germinates and grows rapidly with autumn rains.

The fact that barley grass seeds penetrate the eyes, nostrils, gums and skins of sheep has frequently been observed and the harmful effect speculated upon but not documented. Until recently, the only recorded data, of barley grass damage were the reductions in pelt and wool value obtained through meat processing works. In order to decide whether barley grass should be controlled or not, it is desirable to compare the costs of its effects on stock with the cost of its control. This paper summarizes trial work assessing damage caused by barley grass and the benefits obtained by control measures.

\section{METHODS}

Data on the effects of barley grass were obtained from studies of farm flocks of sheep and lambs during summer and from replicated paddock-scale trial work on herbicidal control in Hawke's Bay and Waikato over a four-year period. In all cases liveweight gains and seed damage were recorded every one to thres weeks through the seeding period. Herbicide trials were 
laid down on 0.2 ha paddocks and treatments used were propyzamide $(0.5 \mathrm{~kg} / \mathrm{ha})$, carbetamide $(2.0 \mathrm{~kg} / \mathrm{ha}), 2,2-\mathrm{DPA}(2.0 \mathrm{~kg} / \mathrm{ha})$, ethcfumesate $(2.0 \mathrm{~kg} / \mathrm{ha})$ and TCA $/ 2,2$-DPA $(5.1 / 0.92 \mathrm{~kg} / \mathrm{ha})$ and untreated control. Each treatment was applied during winter and replicated three or four times. In the farm flock studies comparisons were made amongst animals that were equally exposed to barley grass. Seed in the eyes was removed at each inspection (1- to 3-weekly intervals) to avoid excessive stock losses and stock was drenched periodically for worm control.

\section{RESULTS AND DISCUSSION}

\section{Barley Grass Seed DAMAge}

The most serious consequence of barley grass is the damage caused by seed to stock, particularly young sheep. Most. of the data presented here have been obtained from paddocks with one million or more barley grass seed-heads $/ \mathrm{ha}\left(100 / \mathrm{m}^{2}\right)$ but effects were recorded from as low as $10^{5}$ seed-heads/ha $\left(10 \mathrm{~m}^{2}\right)$.

As soon as the barley grass ripened and shed seed, between mid-December and mid-January, there was a check in liveweight gains of lambs. Depending on severity of infestation this could

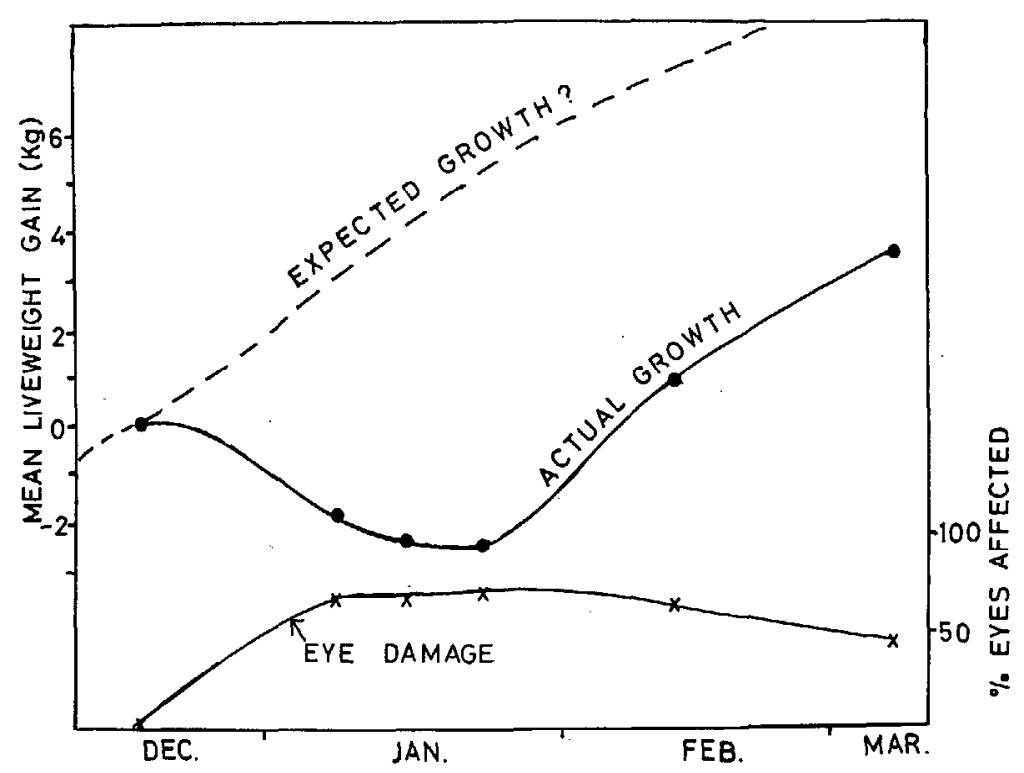

FIG. 1: Mean livew eight gain of $\mathbf{2 8 0}$ lambs in Haw ke's Ray during the "barley grass season" and the corresponding incidence of eye damage. 
be a cessation of liveweight gain or even loss of weight. Figure I shows the mean liveweight gain of a flock of 280 lambs in Hawke's Bay during the "barley grass season" of 1974-5. There was no unaffected flock for comparative growth rate but feed was adequate throughout and data obtained from a replicated herbicide control trial show a similar pattern from the lambs on untreated paddocks but not in the absence of barley grass (Fig. 2) (Hartley and Atkinson, 1972).

\section{SEED IN EYES}

The incidence of seed in the eyes is superimposed on Figs. 1 and 2 and shows the relationship between eye damage and growth depression. At the onset of the barley grass seeding period, weight losses were strongly correlated (1\% level of significance) to seed damage to the eyes and, in the flock in Hawke's Bay, losses of $2.5 \mathrm{~kg} / \mathrm{lamb}$ in three weeks were recorded from this cause (Hartley and Bimler, 1975). Later in the season eye damage became less well related with weight loss but by mid-February the $5 \%$ of the flock that had avoided seed in the eyes throughout had

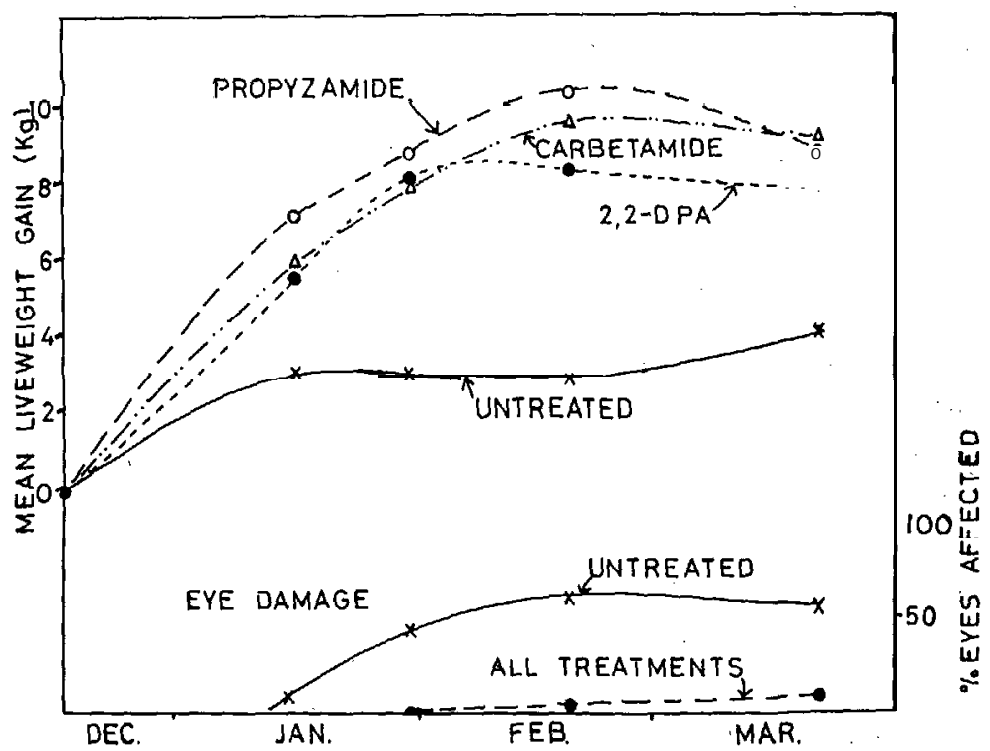

FIG. 2: Mean liveweight gains of lambs on four herbicide-treated pastures in Waikato and the corresponding incidence of eye damage. Stocking rate 35 lambs/ha (21 in means). 
gained nearly $2 \mathrm{~kg}$ more per head than the rest of the flock. Throughout January, 1445 seeds were removed from one flock (mean No. 260 lambs) or 5.5 seed per lamb. Eighty-one percent of the eyes were affected by seed and $38 \%$ were probably blinded. However, $44 \%$ of the damaged eyes recovered completely by March, including $23 \%$ of those previously rated blind. During the period of seed shed, $14 \%$ of the flock died, probably as a consequence of seed damage causing blindness and encouraging fly strike since death's ceased when new seed damage no longer occurred.

The flock was exposed to high infestations of barley grass seed ranging from $10^{6}$, to $10^{\prime}$ seed-heads/ha but high frequencies of eye damage' have been recorded where the incidence of barley grass was less. For example, $70 \%$ of the eyes were affected by $9 \times 10^{5}$ seedheads/ha $\left(90 / \mathrm{m}^{2}\right)$ (Hartley and Atkinson, 1972) and nearly 50\% affected by $6 \times 10^{5}$ seed-heads/ha $\left(60 / \mathrm{m}^{2}\right)$ (Hartley and Atkinson, 1973a). This earlier work also showed that the average weight gain of all lambs with any eye damage due to seed, however slight, was $0.8 \mathrm{~kg}$ less than the mean weight gain of the unaffected animals, during summer.

\section{BODY IRRITATION}

Body irritation 'from barley grass seed affects both growth rates and pelt and wool values. Figures have been put on pelt and wool devaluation of around $\$ 500000$ per annum (Rumball, 1970; Shugg and Vivian, 1973) but this may be minor compared with loss of productivity. Accurate measurements of the effect of seed irritation to the skin is difficult to obtain but there are data that indicate a reduced liveweight gain during the summer of 4 to $5 \mathrm{~kg} / \mathrm{lamb}$ resulting from 100 to 200 seed puncture's to the pelt (Hartley and Atkinson, 197315). Mean numbers of' seed punctures per pelt received by stock from one Hawke's Bay property range from 50 to 500 according to breed of sheep and density of barley grass. The data did not include seed penetration of parts of the body excluded from the processed pelts - e.g., legs, neck and face.

\section{NoSe AND Mouth Damage}

Seed was found up the nostrils of a few lambs (some may have escaped detection) and by mid-February the affected lambs had gained $0.82 \mathrm{~kg}$ /head less than the mean for the rest of the group (Hartley and Bimler, 1975): As some seed damage to nostrils 
may have goae undetected and the stock included in the group mean, the real effect may well have been greater.

Seed in the gums had little affect on the growth rate though there appeared to be a slight positive correlation. This could have arisen as a consequence of greater feeding activity leading to better growth rate and more seed in the gums. However, where damage to the lips and cheeks was severe enough for them to remain scarred in mid-February, the affected lambs had then gained $0.66 \mathrm{~kg} / \mathrm{head}$ less than the rest of the flock. There was no detectable relationship between nose/mouth damage and eye/ pelt damage.

\section{BrEed AND AgE OF SHEEP}

As far as eye damage was concerned, lambs were nearly ten times moire vulnerable than ewes of comparable breed, and breed differences were also marked. The clean-faced Border Leicester type lambs suffered significantly less damage (about one-third) than Southdown-cross lambs (Hartley and Bimler, 1975). Wool type also affected the degree of pelt damage suffered, with Border Leicester again having a considerable advantage over Down and Merino types which suffered 10 to 20 times more damage (Hartley and Atkinson, 1973b).

\section{Bardey Grass Spectes}

Some of the trial work was conducted on sites occupied by common barley grass, Hordeum murinum L., and Mediterranean barley grass, $\mathrm{H}$. geniculatum All. (previously called $\mathrm{H}$. hystrix Roth.). Both species were equally damaging to the eyes and skin but damage to the nostrils and gums was caused exclusively by H. geniculatum (Hartley and Bimler, 1975).

\section{Chemical Control of Bariey grass}

A number of herbicides give reasonable control. of barley grass but all have some effect on other pasture species. Their use is, therefore, generally associated with a reduction in pasture dry matter production and a change in pasture composition. In order to ascertain whether reduction in pasture production is offset by reduction in barley grass damage, herbicide trials have been conducted on paddock scale so that the effect can be measured via sheep. These trials have shown that where barley grass infestation is severe considerable reductions in dry matter production 
resulting from treatment may not result in corresponding reductions in stock performance (Hartley et al., 1974). Control of barley grass, even when associated with loss of pasture production, can result in increased growth rates of lambs (Fig. 2). Over the period shown in Fig. 2 mean dry matter production from treated paddocks was $14 \%$ less thaa that of control paddocks but clover percentage was increased.

Barley grass control, as measured by seed-head numbers,, by the herbicides used was generally good. A very heavy infestation of barley grass in Hawke's Bay was 98\% controlled by one application of ethofumesate and virtually eliminated by a second application the following year. However, control in Waikato, though up to $98 \%$, has been as low as $80 \%$ on light infestations. This herbicide bad no apparent effect on ryegrass but checked clover growth and consequently pasture production. However, the ryegrass-dominant swerd was more resistant to re-establishment of barley grass seedlings than the clover-dominant sward resulting from other treatments. Propyzamide, carbetamide or 2,2DPA bave given barley grass control of 92 to $99 \%$ but they also weakened ryegrass and left clover dominance. Under conditions suitable to summer clover growth, these treatments gave good sheep feed but were vulnerable to invasion by weeds, including barley grass, and the small surviving population multiplied rapidly. The TCA/2,2-DPA mixture left a good pasture balance but was less reliable for barley grass control ranging from well over $90 \%$ to less than $70 \%$ control.

\section{CONCLUSIONS}

The evidence collected on barley grass seed damage to lambs indicates this to cause serious growth depression for about two months during summer, reducing liveweight gains by 6 to $8 \mathrm{~kg}$ per lamb. Study of affected animals during winter has shown that compensatory growth does not fully make up the deficit.

Where lambs are reared for fat lamb production and are not sold before the barley grass season commences, they are unlikely to reach fat con\&ion for at least two to three months. This dday will keep them on the farm all summer, normally a period 04 feed shortage, and subject them to danger from facial eczema. The main flock studied here suffered serious losses from facial eczema, with over $30 \%$ having to be killed and only $46 \%$ sold fat. Barley grass, therefore, directly and indirectly accounted for the loss of nearly half the flock. These losses may be exception- 
ally high but they do demonstrate the potential danger of barley grass to young sheep.

Herbicide control of barley grass gives valuable protection where barley grass incidence is dangerously high. Most herbicides cause pasture depression after application in the later winter, which is undesirable but, given favourable weather conditions, may actually increase pasture production in the summer (when barley grass would senesce). On properties badly affected with barley grass, therefore, herbicide treatment of some paddocks would be 'advantageous, to carry and lambs whioh cannot be sold before the barley grass seeds.

Selection of breed of sheep could considerably reduce the detrimental 'effects of barley grass and young sheep should be kept away from areas of seeding barley grass.

\section{REFERENCES}

Hartley, M. J.; Atkinson, G. C., 1972. Proc. 25fh N.Z.W eed \& Pest Control Conf.: 23-S.

92-7.'

$87-91$;

Hartley, M. J.; Atkinson, G. C.; Bimler, K. H.; Douch, G. A., 1974. Proc, 27th N.Z. Weed \& Pest Control Conf.: 74-8.

Hartley, M. J.; Birder, K. H., 1975. Proc. 28th N.Z. Weed \& Pest Control Conf.: $2 \cdot-6$.

Rumball, P. J., 1970. Proc. 23rd N.Z. Weed \& Pest Control Conf.: 77-82.

Shugg, A. W.; Vivian, G. W., 1973. Proc. 26th N.Z. Weed \& Pest Control Conf : 82-6. 